\title{
Family Interdependencies and the Family Physician
}

\author{
Arthur L. Kellerman, MD, MPH, and Gerry Fairbrother, PhD
}

The Institute of Medicine (IOM) just released its third report from its Consequences of Uninsurance project. This report, Health Insurance Is a Family Matter, ${ }^{1}$ explores interdependencies of health insurance, health, and well-being among family members. Its central message is important for family physicians: the physical, psychosocial, and financial health and well-being of the whole family can be adversely affected by even one members' lack of health insurance.

The first IOM report, Coverage Matters, ${ }^{2}$ included an overview of who is uninsured, described the dynamics of health insurance in this country, and showed the persistence of a large uninsured population. The second report, Care Without Coverage: Too Little, Too Late, ${ }^{3}$ provided a thorough review of research conducted in the past two decades on the effect of health insurance status on adult health. This third report extends the analysis from the individual to the country's most important social and economic unit-the family.

Why focus on the family? The family is the unit in which resources are tapped and often exceeded when unexpectedly large health care costs are incurred. Families make the decisions about how much health care coverage is affordable. Through families parents make choices about seeking health care for their children.

The well-being of the whole family can be adversely affected if even one member lacks health insurance. One of every five American families has at least one member who has been uninsured for the past year. Roughly 58 million persons are either uninsured themselves or are living with a family member who is uninsured.

Submitted 14 October 2002.

From the Department of Emergency Medicine, Center for Injury Control (ALK), Rollins School of Public Health, Emory University, Atlanta, the Institute of Medicine Committee on the Consequences of Uninsurance (ALK), the Division of Health and Science Policy (GF), New York Academy of Medicine, New York, and the Family Impacts of Uninsurance Subcommittee (GF), Institute of Medicine Committee on the Consequences of Uninsurance. Address reprint requests to Gerry Fairbrother, $\mathrm{PhD}$, Division of Health and Science Policy, New York Academy of Medicine, 1216 Fifth Ave, New York, NY 10029.
Within the family, parents decide whether to seek care for their children. The manner in which parents use the health care system for themselves can affect whether their children will receive needed and timely care. For instance, if a parent has had negative experiences with the health care system, he or she might be reluctant to seek care for a child until the symptoms become more severe.

For families gaps in health care coverage can occur in a variety of ways. Public insurance programs might cover children but not their parents, whereas employment-based coverage might leave some or all family members uninsured in the event of job change, illness, divorce, or death. Both public and employment-based insurance coverage typically ends for children around the age of 19 years, just as young adults are entering the job market. Young workers are less likely than older workers to find jobs that include health benefits, and indeed young adults between the ages of 18 and 24 years have the highest uninsurance rates of any agegroup.

Gaps in coverage are common. One fifth of American families experience at least 1 year in which one or more family members lack health insurance. Shorter gaps in coverage are even more common. When both parents are insured, their children usually are insured as well. Only one family in three, however, has coverage for their children if neither parent has health insurance. Singleparent families are less likely than two-parent families to have all family members covered, and they are twice as likely to have no family members insured. The report found there are approximately 9 million uninsured parents and 8 million uninsured children in the United States. Nearly 5 million of these children-more than one half-are eligible for Medicaid or the State Children's Health Insurance Program (SCHIP), but they are not enrolled.

There is clear evidence of family interdependencies for health insurance, health care use, and family health, and well-being. If parents are insured, children are more likely to be insured. This relation holds true whether it applies to the population at 
large or to low-income groups who are eligible for public assistance. All states have expanded health coverage to children, but only some have extended coverage to the child's parents as well. Those states that have expanded coverage to parents have seen greater increases in enrollment of children, even though the latter were eligible all along. Moreover, there is mounting evidence from a variety of sources that if parents use health care, children are more likely to use health care. Finally, with respect to family well-being, there is a long-standing body of research which shows that the health of the mother affects the health and well-being of her children. For example, there is clear evidence that parents' mental health strongly affects child-rearing practices.

The report reaches four major conclusions:

1. The current hodgepodge of employmentbased and public insurance leaves gaps in coverage for many families.

2. Families with at least one member uninsured for the previous year often cannot afford to pay major health care bills or insurance premiums. Many will therefore avoid seeking care.

3. Children whose parents do not have health insurance are less likely to be insured and less likely to receive appropriate health care, even if the child is eligible for coverage.

4. Pregnant women, newborns, and children without health insurance have worse access to care, receive fewer services, and often have poorer health outcomes.

Family physicians, unlike most other medical specialists, treat every member of the family. Par- ticularly in practices serving low-income populations, the family physician is likely to care for families in which some, but not all, of its members have health insurance, because (according to the report) public programs are more likely to insure children and not their parents. Additionally, many low-wage workers might be able to afford only individual coverage (if it is offered at all) and not the worker's share of the premium for family coverage. We also know that up to 5 million children who are eligible for public insurance are not enrolled in these programs. These findings indicate the need for stronger outreach and enrollment of families. The family physician's office is one logical spot to start this process by encouraging families to sign up for SCHIP or Medicaid.

Taken together, the evidence presented in Health Insurance Is a Family Matter clearly shows the importance of health insurance to the health and well-being of the family in its entirety. It also points out the importance of developing public health insurance policies with the entire family in mind. These insurance issues should be on the agenda for organizations of family physicians at local, state, and national levels.

\section{References}

1. Institute of Medicine. Health insurance is a family matter. Washington, DC: National Academy Press, 2002a.

2. Institute of Medicine. Coverage matters: insurance and health care. Washington, DC: National Academy Press, 2001.

3. Institute of Medicine. Care without coverage: too little, too late. Washington, DC: National Academy Press, 2002b. 